\title{
Ética e sigilo profissional
}

\author{
Ethics and Professional Secrecy
}

\section{Simone Sobral Sampaio* Filipe Wingeter Rodrigues**}

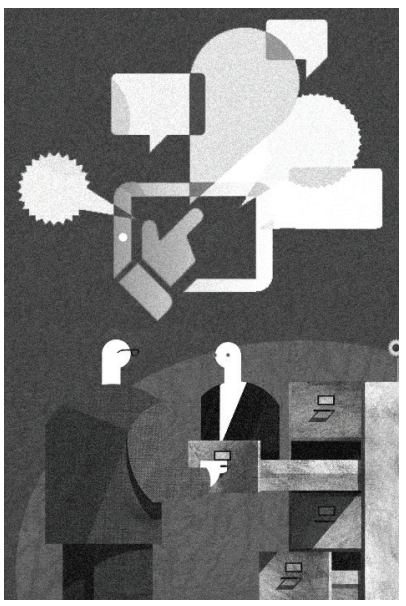

Resumo: Este artigo problematiza o sigilo profissional em uma perspectiva ética com o objetivo de apresentar a sua caracterização e complexidade a partir de alguns elementos contemporâneos presentes na sociedade brasileira, como o domínio midiático sobre a vida privada da população pobre, as exigências postas ao assistente social na relação direito e dever no contexto institucional e legal, assim como as perguntas que sinalizam sua pertença ao campo ético.

Palavras-chave: Sigilo profissional. Ética. Direito.

\begin{abstract}
This article deals with the questioning of the professional secrecy from an ethical point of view in order to present its characteristics and complexity from contemporary elements that are present in the Brazilian society, as the control the media has over poor people's private lives, the requirements over the social workers for the relationship between rights and duties in the legal and institutional context, as well as the questions belonging to the ethical area.
\end{abstract}

Keywords: Professional secrecy. Ethics. Law.

* Assistente Social, professora doutora do departamento de Serviço Social da Universidade Federal de Santa Catarina (UFSC), Florianópolis-SC, Brasil.PhD.E-mail: simone.s@ufsc.br.

** Mestrando em Serviço Social no Programa de Pós-Graduação em Serviço Social (PPGSS) pela UFSC.E-mail: fw_rodrigues@yahoo.com.br. 


\section{Introdução}

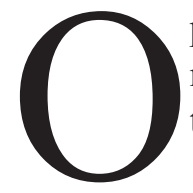

presente artigo trata da análise fruto dos resultados parciais obtidos na realização do projeto de pesquisa, em curso, sobre a atuação do assistente social no espaço sociojurídico.

Muitos aspectos envolvem algo que é, aparentemente, simples: a manutenção de um segredo. Se essa atitude já envolve questões e dilemas quando em relação interpessoal, pois implica desde a possibilidade e o dever daquele que guarda o segredo de se omitir em revelá-lo até a necessária proteção da intimidade do sujeito que apresenta o aspecto de sua vida que não quer que seja conhecido por outrem, todos esses aspectos complexificam-se ainda mais nos termos do sigilo profissional.

Pelo exercício de sua profissão, cabe ao assistente social o direito de não revelar a informação obtida do usuário que o fez na confiança de resguardo da matéria sigilosa. Na língua portuguesa, segredo e sigilo são sinônimos. Ao verificar as diversas definições de sigilo profissional pode-se observar sua similitude tanto enquanto direito como dever do profissional em não divulgar informações colhidas ou obtidas em decorrência de seu trabalho.

Não são todas as profissões que devem a obrigação do sigilo e isso já seria revelador da disposição social que é atribuída a algumas profissões de terem o dever e o direito de mantê-lo.

Ora é consenso que o profissional conheça todos os elementos necessários para o bom cumprimento de seu trabalho, desde as condições institucionais até as informações obtidas na sua relação com o usuário. O sigilo profissional não é absoluto, no caso do Serviço Social, esse elemento abre a possibilidade de esse profissional avaliar, subjetivamente, se deve manter ou divulgar o fato sigiloso, devendo prevalecer o disposto no Código de Ética Profissional do Assistente Social atentando para o conteúdo ético-político dos princípios que o regem.

A análise do sigilo profissional a partir da ética mostra que se está diante de algo complexo, que não se limita a um preceito legal. Quer dizer, o seu entendimento remete as questões: para quem?; com qual necessidade?; para quê? e em que condições? Essas questões não podem ser pensadas abstratamente, mas sim a partir das situações concretas nas quais estão inseridas, pois interrogam a multiplicidade de demandas que lhe são colocadas na comunicação de uma informação.

Dessa forma, as reflexões que serão propostas aqui não pretendem ser nem um guia de boas práticas, nem tampouco um catálogo de comportamento, mas problematizar esse importante aspecto presente no exercício profissional. 


\section{Desenvolvimento}

O sigilo profissional trata de uma informação a ser protegida, impõe uma relação entre privacidade e publicidade, cujo dever profissional se estabelece desde a se ater ao estritamente necessário ao cumprimento de seu trabalho, a não informar a matéria sigilosa.

Partindo da hipótese que a esfera privada da vida de alguns indivíduos tende a ser confiscada em maior medida que a da vida de outros, pode-se dizer que o lugar de tensão entre o respeito à vida privada, sem discriminação, e as escolhas da sociedade estão desaparecendo; é como se todos os meios fossem válidos desde que justificados.

A vida das pessoas pobres sofre maior interferência e intervenção do poder público e da mídia sob alegação de segurança e proteção. Na ordem atual em que a mídia explora largamente a exposição da vida dos indivíduos pobres, a banalização da questão social e o tratamento sensacionalista dispensados pela mídia fortalecem a despolitização e a naturalização dessas existências, reforçando um espaço público espetacular que se faz como exposição vazia da vida privada.

Os pobres, ou melhor, a sua "imagem" tem sido alvo devidamente cuidado pela rede televisiva brasileira com a justificativa ou alegação de uma eficiente cobertura da realidade. Com esse propósito, por exemplo, são reproduzidos dezenas de programas televisivos, os quais têm como carro-chefe a exposição dos dramas cotidianos de pessoas pobres, criando uma imagem dessa população e utilizando-a como produto mercadológico. A variedade como é manipulada a existência da população pobre percorre muitos programas, desde o conhecido telejornal policial, ${ }^{1}$ passando pelo talk show, até chegar aos palcos dos programas de auditório, ${ }^{2}$ e outros meios que se pretendem mais sutis (Sampaio, 2006).

Não é difícil constatar que a programação televisiva está repleta, em seus diversos horários e programações (desde os menos concorridos até os que atingem melhor ibope) de histórias reais de infortúnio e reclamações variadas. Vidas desti-

1. O estilo conhecido como "mundo cão na TV" foi inaugurado em 1991, pelo programa Aqui Agora (SBT). A fórmula perdeu espaço devido à queda na audiência e a fuga dos anunciantes, mas seria apressado prever o seu desaparecimento. Dentro desse filão destacaram-se o Cidade Alerta (Record), Repórter Cidadão (Rede TV), e Brasil Urgente (Band), que está no ar desde 3/12/2001.

2. Quadros emblemáticos são observados: o "Se vira nos trinta" (no programa Domingão do Faustão, Globo) e "Agora ou nunca" (no programa Caldeirão do Huck, Globo), para ficar apenas nos que apresentam maior audiência. 
nadas a passar ao largo podem na TV denunciar ou solicitar. Esse fato poderia à primeira vista ser motivo suficiente de comemoração de uma destinação pública de um espaço no programa televisivo ou, então, de uma sensibilidade social. Mas será que devemos mesmo comemorar essa explosão de realidade na telinha?

É na contracorrente e na crítica a esse intenso processo de espetacularização da pobreza que se encontram os valores éticos que fundam o Código de Ética Profissional do Assistente Social, aliado à compreensão da pessoa a ser atendida como sujeito de direito, sendo que a prática profissional se estabelece para recuperar um direito que já foi ferido ou, na maioria das vezes, nunca existiu de fato.

Nesse quadro, o assistente social trabalha com profissionais de outras áreas, que ainda que tenham o sigilo profissional circunscrito em seus códigos, não estão sujeitos às mesmas obrigações, apresentam objetivos diferentes e, ainda, lógicas e prioridades distintas das do Serviço Social. O assistente social atua em circuitos em que as informações devem ser partilhadas e, ao mesmo tempo, em que a confidencialidade é, legalmente, autorizada.

Outro elemento que também deve ser considerado é a diversidade de interpretações, nem sempre compatíveis, alicerçadas sobre diferentes valores em jogo. Além do que, o sigilo profissional no domínio do que se convencionou chamar "social" é menos digno de nota, sofre uma hierarquia menor que o referente a outras profissões, como advogados e médicos. É como se quando o "cliente" dessas profissões fosse mais digno do que quando usuário do Serviço Social.

Aliada a todos esses elementos somam-se outras questões: o que fazer quando as palavras repassadas são deformadas, retiradas do contexto que foram ditas e apropriadas juridicamente para um fim que estava de antemão definido? O que fazer diante do dever de testemunhar sem que isso abale o igual dever, de proteção da infância, por exemplo? Como assegurar a proteção ao anonimato e resguardar a qualidade da informação e a segurança dos envolvidos? Como definir dentro do que foi dito, o que deve ser matéria de sigilo? Quais as informações que realmente contribuem para o direito reclamado?

Resumindo, em que circunstâncias o assistente social deve resguardar o sigilo profissional? Essa pergunta possui diversos vetores: a obrigação jurídica, as regras de determinada instituição, as escolhas éticas do profissional, o estabelecido pelo Código de Ética Profissional, a própria relação entre o usuário do serviço e o assistente social, a realidade que suscita o sigilo. Por tudo isso, a resposta pode parecer simples, mas não é. Não se trata apenas de uma decisão no âmbito da lei. Quer dizer, talvez não se trate de definir esquematicamente o que cabe à instituição e o que cabe ao profissional, mas refletir anteriormente qual é o direito que está 
sendo reclamado pelo demandante. E, nessa perspectiva, definir o limite do sigilo. Para Ceneviva (1996, p. 17), o dever ético cujo cumprimento é atribuído a uma pessoa em razão de sua profissão lhe imputa uma atitude de "obter apenas a informação necessária para o cumprimento da missão profissional, e não mais que isso". Isso serve para pensar não apenas a obtenção da informação, mas ainda a veiculação desta ao que for necessário para o cumprimento do direito.

A resposta adequada para a pergunta "dizer ou não dizer?" é posterior à atitude profissional que a princípio deve procurar não ir além do que é necessário para o cumprimento do objetivo profissional.

Em algumas situações, a troca e o compartilhamento de informações nem sempre se estabelecem entre profissionais que possuem a obrigação do sigilo, sendo diferentes os papéis e as responsabilidades de cada um. Por outro lado, geralmente o assistente social é um trabalhador assalariado em uma instituição, inserido em uma equipe e em uma rede maior que tem outros profissionais, outras instituições, que se articulam justamente por meio da colaboração e da comunicação de informações. Nesse conjunto, o que pode ou não ser dito sem caracterizar violação do sigilo profissional?

Esse cuidado deve ser orientado na comunicação restrita apenas ao necessário ao interesse do direito do usuário, que deve estar de acordo ou, pelo menos, informado do processo que segue, e dito a outro profissional que também esteja submetido ao sigilo profissional. Isso pode gerar dúvidas sobre o que deve ser matéria de sigilo profissional. E, principalmente, a seguinte reflexão: se a função social de uma informação fosse a mesma, seria irrelevante se ela fosse colhida pelo policial, pelo advogado, pelo médico, pelo assistente social ou pelo juiz.

\section{Sigilo/segredo profissional}

Como se sabe, o sigilo profissional ${ }^{3}$ — a guarda de informações obtidas em razão do exercício profissional, de tudo aquilo que lhe foi confiado como sigilo, ou o que veio a ser conhecido devido seu estatuto profissional - está previsto em

3. O termo sigilo tem origem do latim sigillum, que significa selo ou segredo. Segundo Ceneviva (1996, p. 22), "o sigilo, [...] além do sinônimo de segredo, é também o selo e o respectivo sinete, ligando-se diretamente ao étimo, como selo aposto para garantir a inviolabilidade de documento ou de seu envoltório. Mantém-se com esse significado na espécie de sigilo de correspondência, com o qual, aliás, terminou estendido à comunicação telegráfica, à transmissão de dados e à conversão telefônica". 
muitos dispositivos legais (a Constituição Federal brasileira, o Código Penal, o Código Civil, o Código de Processo Penal, a Lei das Contravenções Penais e o Código de Processo Civil).

Constitucionalmente, ninguém será obrigado a fazer ou deixar de fazer algo, senão em virtude da lei, e que são invioláveis a intimidade, a vida privada, a honra e a imagem das pessoas. Esse entendimento norteia os dispositivos legais que se referem ao sigilo profissional, em particular o sigilo médico.

A referência a esses dispositivos legais nos é útil nessa reflexão para chamar a atenção que o direito à confidencialidade é tanto um direito da pessoa, como também uma responsabilidade profissional. Em outros termos, a existência do sigilo profissional interessa a toda sociedade, pois é condição indispensável para o trabalho do profissional, na medida em que essas ações encarnam um interesse da sociedade, definido historicamente.

No Brasil, todos os Códigos de Ética do(a) assistente social instituídos no decorrer da história da profissão trataram sobre a questão do sigilo ou de seu sinônimo segredo, ainda que representasse uma forte vinculação moral da doutrina cristã. O Código de Ética de 1947, em sua seção primeira, item 2, preconizava como dever fundamental "guardar rigoroso sigilo, mesmo em depoimentos policiais, sobre o que saiba em razão de seu ofício". Não havia o esclarecimento sobre em que condições determinadas informações sigilosas poderiam ser reveladas.

No Código de Ética de 1965, em seu capítulo terceiro, tratava-se especificamente do segredo profissional.

Art. 15. O assistente social é obrigado pela Ética e pela Lei (art. 154 do Código Penal) a guardar segredos sobre todas as confidências recebidas e fatos de que tenha conhecimento ou haja observado no exercício de sua atividade profissional, obrigando-se a exigir o mesmo segredo de todos os seus colaboradores. (CFAS, 1965, p. 3)

A permissão da revelação de um segredo profissional, previsto nesta normativa, era concedida apenas para "evitar um dano grave, injusto e atual ao próprio cliente, ao assistente social, a terceiros e ao bem comum" e "após terem sido empregados todos os recursos e todos os esforços, para que o próprio cliente se disponha a revelá-lo", dentro do estritamente necessário, conforme preceituava os parágrafos $1^{\circ}, 2^{\circ}$ e $3^{\circ}$ do artigo $15^{\circ}$ do dito Código. A questão do sigilo profissional nesse Código representava uma obrigação moral e legal ao(à) assistente social.

No Código seguinte, de 1975, o(a) assistente social deveria observar o segredo profissional no seu exercício, sobre todas as confidências recebidas, fatos e 
observações escolhidas no seu exercício, abstendo-se de transcrever informações de natureza confidencial, e tal como previsto no Código de Ética anterior, era admissível a quebra de sigilo apenas quando pudesse causar um dano grave ao "cliente", ao assistente social ou ao bem comum.

Para Barroco (2010), o Código de Ética de 1986 tornou-se uma marca da opção da profissão por uma prática vinculada aos interesses da classe trabalhadora, o que fica evidenciado no parágrafo primeiro do artigo $4^{\circ}$ do referido Código: "A quebra do sigilo só é admissível, quando se tratar de situação cuja gravidade possa trazer prejuízos aos interesses da classe trabalhadora" (CFAS, 1986, p. 4).

No que estabelece o atual Código de Ética Profissional do Assistente Social (1993), a revelação do sigilo profissional implica uma falta que tem sanções disciplinares. Nesse Código de Ética, o seu capítulo V trata diretamente do sigilo profissional como direito e dever profissional, sendo que o artigo 18 estabelece: "A quebra do sigilo só é admissível, quando se tratar de situações cuja gravidade possa, envolvendo ou não fato delituoso, trazer prejuízos aos interesses do usuário, de terceiros ou da coletividade". No parágrafo único diz que a revelação será feita dentro do estritamente necessário. Tem-se ainda o Capítulo VI, das relações do assistente social com a justiça, em que o profissional pode declarar obrigação com a guarda do sigilo profissional. Quer dizer, não se trata apenas de um direito, mas de uma obrigação.

Barroco e Terra (2012, p. 92) afirmam que "o sigilo profissional é parte de todas as profissões liberais e sua polêmica decorre da possibilidade da quebra do sigilo, pois coloca dúvidas acerca de sua justificação, em outras palavras: em quais situações seria correto quebrar o sigilo?"

É possível acontecer situações em que o sigilo profissional se opõe à requisição institucional formulada, geralmente apresentada como motivo legítimo. Mas o que é um motivo legítimo?

Sobre isso é ilustrativo o ocorrido entre 1830-36, no momento revolucionário francês de construção republicana, em que os monarquistas, representantes da ordem social vigente, exigiram que lhes fossem repassados os nomes dos insurgentes que se socorreram em um hospital de Paris. O responsável pelo hospital respondeu o seguinte à exigência feita: "Eu não vi nenhum insurgente em meu hospital, vi apenas feridos". ${ }^{4}$

4. “Je n'ai pas vu d'insurgés dans mes saltes d' hôpital, je n'ai vu que des blessés”. Dupuytren, Bibliothèque Nationale de France. Disponível em: < http://catalogue.bnf.fr/ark:/12148/cb32798517r>. Acesso em: 4 nov. 2013. 
Não são raras as vezes em que o assistente social se encontra diante do conflito sobre qual a melhor decisão a ser tomada. Esses conflitos supõem valores que podem se contrapor ao instituído, que podem estar em desacordo com a sua equipe de trabalho, bem como com a instituição empregadora. Esses conflitos se colocam no coração da ética, suscitados pela pergunta "o que fazer?" Implica tanto decidir em nome de um princípio, como também estar ciente da responsabilidade por sua decisão e as suas consequências.

Segundo Silva (2007), para explicitar a ética (que está implícita na prática profissional) será necessário refletir sobre os valores pelos quais os assistentes sociais desenvolvem suas ações, perceber qual o significado desses valores para si, bem como as finalidades e repercussões de sua intervenção, ou seja, analisar a adequação dos atos às consequências que os mesmos podem produzir.

Consequentemente, o profissional, adotando um posicionamento ético-político, deve analisar as atribuições que lhe são confiadas, compreender as problemáticas que se colocam na sua ação, as atividades que desenvolve, i.e., verificar quais os valores subjacentes à sua intervenção de modo a incorporá-los na sua prática quotidiana, terá igualmente que estar ciente de que as tomadas de decisão proporcionam o aparecimento de dilemas, visto, em muitos casos, qualquer que seja a "escolha", esta pressupõe como resultado uma ação indesejada. (Silva, 2007, p. 107; grifo do autor)

Uma decisão ética resulta de uma deliberação, de uma escolha consciente diante da pluralidade de elementos que envolvem determinada questão. Sendo que sua decisão terá implicações para si mesmo, para o usuário do serviço, para a instituição e para o conjunto da sociedade. Por isso é preciso considerar a opinião do usuário, se a informação tratada é ou não confidencial, seu objetivo profissional, para que serve o compartilhamento de tal informação, e com quem compartilhá-la; e, ainda, o que é melhor para garantir determinado direito.

Na relação com o usuário, este deve ser colocado a par sobre a situação que demanda suas informações, para melhor se posicionar ou até mesmo se recusar a prestar as informações solicitadas. É importante que o usuário seja reconhecido como sujeito, de modo que tome conhecimento do conteúdo daquele trabalho e que as informações prestadas não serão banalizadas, ao contrário, pois estão sendo ditas a um profissional que possui qualificação, competência e ética profissional, o que pode permitir a construção de uma relação de confiança mútua.

Reforça-se o termo confiança mútua para dizer também que as pessoas concernentes, em geral aquelas que sofrem de diferentes tipos de privação, principal- 
mente a falta dos direitos sociais, têm igualmente direito ao respeito, no avesso do que lhe são comumente destinados, como a discriminação, a desconfiança, presumidas culpadas e perigosas. Não é apenas o dito que é matéria de sigilo. Algumas vezes nos deparamos com situações em que a palavra não é dita, mas é o corpo que fala por meio de gestos que mostram o constrangimento sofrido. Nesses casos, é o silêncio que aparece.

\section{Considerações finais}

O sigilo profissional não pode vir separado da reflexão ética, como se fosse uma simples questão técnica ou mesmo procedimental. As questões que despertam e os dilemas que apresentam ao cotidiano do exercício profissional impelem a necessidade de uma postura analítica da realidade, da clareza do objetivo profissional, que não se deixe burocratizar ou tecnificar, de ações norteadas por princípios éticos no lugar de preconceitos, e de uma competência que não reforce a subalternidade dos usuários do Serviço Social, ao contrário, construa possibilidades de reconhecimento de direitos.

Nesses termos, a ética recoloca a necessidade da reflexão e da crítica, fazendo ver que nem a moral e nem a lei são dados a-históricos, naturais e imutáveis. Ela perpassa todos os campos que estruturam a sociedade, pois que estes são igualmente produto e produtores das ações dos sujeitos. A ética interroga as leis, as competências e qualificações profissionais, conforma uma deontologia profissional. E, sobretudo, nos pergunta o que estamos fazendo de nós mesmos?

A ética e a política possuem uma relação ineliminável, pois a resposta à pergunta "o que fazer?" sempre é acompanhada da não menos difícil reflexão sobre "o que eu posso fazer?". Porém nesse caso o poder não é apenas o lugar do instituído e da autoridade, mas verbo presente no constante processo de construção de autonomia profissional.

Recebido em 7/11/2013 - Aprovado em 2/12/2013 


\section{Referências bibliográficas}

ASSOCIAÇÃO BRASILEIRA DE ASSISTÊNCIA SOCIAL (ABAS). Código de Ética Profissional do Assistente Social aprovado em 29 de setembro de 1947. Disponível em: $<$ http://www.cfess.org.br/arquivos/CEP_1947.pdf $>$. Acesso em: 8 ago. 2013.

BARROCO, Maria Lúcia Silva. Ética e Serviço Social: fundamentos ontológicos. 8. ed. São Paulo: Cortez, 2010.

; TERRA, S. Código de Ética do/a Assistente Social comentado. Conselho Federal de Serviço Social. In: (CFESS) (Org.). São Paulo: Cortez, 2012.

BRASIL. República Federativa do. Constituição da República Federativa do Brasil: texto constitucional promulgado em 5 de outubro de 1988. Brasília: Senado Federal, Subsecretaria de Edições Técnicas, 2010. 544 p.

CENEVIVA, Walter. Segredos profissionais. São Paulo: Malheiros Editores, 1996.

CONSELHO FEDERAL DE ASSISTÊNCIA SOCIAL (CFAS). Código de Ética Profissional aprovado em 8 de maio de 1965. Disponível em: <http://www.cfess.org.br/arquivos/ CEP_1965.pdf>. Acesso em: 8 ago. 2013.

Código de Ética Profissional do Assistente Social aprovado em 30 de janeiro de 1975. Disponível em: <http://www.cfess.org.br/arquivos/CEP_1975.pdf>. Acesso em: 8 ago. 2013.

Código de Ética Profissional do Assistente Social aprovado em 9 de maio de 1986. Disponível em: <http://www.cfess.org.br/arquivos/CEP_1986.pdf > . Acesso em: 8 ago. 2013. CONSELHO FEDERAL DE SERVIÇO SOCIAL (CFESS). Resolução CFESS n. 273, de 13 de março de 1993. Institui o Código de Ética Profissional dos Assistentes Sociais e dá outras providências. Disponível em: <http://www.cfess.org.br/arquivos/resolução_273-93. pdf>. Acesso em: 8 ago. 2013.

SAMPAIO, Simone Sobral. A questão social na sua versão midiática. In: ENCONTRO NACIONAL DE PESQUISADORES EM SERVIÇO SOCIAL, 10., Anais..., Recife, 2006.

SILVA, Manuel Domingos Menezes da. Mediações éticas na prática quotidiana dos assistentes sociais. Serviço Social \& Sociedade, São Paulo, n. 92, p. 97-117, nov. 2007. 